\title{
Analysis of Neutronic Parameters for Supercell of CANDU Reactor Using MCNPX Code
}

\author{
Afrah EL-Khawlani ${ }^{1}$, Moustafa Aziz Ibrahim ${ }^{2}$ and Ali Ellithi ${ }^{3}$ \\ 1. College of Science, Cairo University, Cairo 12613, Egypt \\ 2. Physics Department, Faculty of Science, High Education, Sana'a, Yemen \\ 3. Nuclear and Radiological Regulatory Authority, Nasr City, Cairo
}

Received: July 17, 2013 / Accepted: August 02, 2013 / Published: August 25, 2013.

\begin{abstract}
MCNPX code has been used for modeling and simulation of a supercell of CANDU Fuel, the supercell consists of two fuel bundle and adjuster rod. The fuel bundle are burnt in normal operation conditions of CANDU reactors. Natural uranium fuel is used in the model. The multiplication factor of the bundle is calculated during fuel burnup. The concentration of both uranium and plutonium isotopes are analysed in the bundle. The worth of the adjuster rod is calculated. Comparison of multiplication factor and worth of the adjuster rod with the previous published references showed good agreement.
\end{abstract}

Key words: Candu, supercell, MCNPX.

\section{Introduction}

The operating CANDU reactors are refueled on power to compensate for the reactivity loss due to fuel burnup. This feature makes the in core fuel management substantially different from that in other reactors which must be refueled during shutdown. Several refueling operations are normally carried out daily, so that refueling is almost continuous. Also, the fuel channels are horizontally aligned, and most of the reactivity devices are located vertically between the two fuel channels, which necessitates a three dimensional modeling of a reactivity device with a fuel channel to generate the cross sections for the reactivity devices. In the core simulation, the presence of the reactivity devices is represented by the difference in macroscopic cross sections of the unit lattice bundle with and without the reactivity devices, which is represented by incremental cross section [1-5].

The reactivity control devices of a CANDU-PHWR

Corresponding author: Moustafa Aziz Ibrahim, Prof. of nuclear engineering, research field: Reactor core calculations. E-mail: Moustafaaai@yahoo.com. consists of adjuster rods, Zone controller units, Mechanical control absorber and shutoff rods. Of these devices mechanical control absorber and shutoff rods are fully withdrawn when a reactor is normally operating at full power. Adjuster rods of stainless steel are however fully or partially inserted into the core during normal operation. Zone controller units regulates the reactor power of each zone by varying the amount of light water in the corresponding compartment. Incremental cross sections are thus considered for zone controller units and adjuster rods [2, 6-8].

The analysis of these effects is performed by a calculation of the control device between two fuel bundles, collectively forming what is known as a supercell. The fuel bundle are burnt in normal operation conditions of CANDU reactors. Natural uranium fuel is used in the model. The multiplication factor, evolution of both Uranium and Plutonium isotopes in the bundle are calculated and analysed [9].

In the following, section III describes the mathematical and computational model of the paper, and section VI shows the results and discussions, 
section IV states the conclusions.

\section{III-Computational and Mathematical Model}

MCNPX computer code package [9] were used to perform the neutronic analysis of the two fuel bundle model [10, 11]. Each element consists of natural uranium in the form of cylindrical pellets of sintered uranium dioxide contained in a zircaloy 4 sheath closed at the each end by an end cap [6]. The 37 elements are held together by end plates at each end to form the fuel bundle. Table 1 illustrated composition and Dimensions of the fuel bundle. The dimensions of one bundle is $28.575 \times 28.575 \times 49.53 \mathrm{~cm}$.

We use the two bundle model [10] and two identical bundle are considered as a supercell in the model. The three-dimensional supercell is shown in Fig. 1 . The lattice assembly geometry contains 37 fuel rods which is shown in Fig. 2. There is an arrangement in the hexagonal shape, a center rod surrounded by three rings of fuel rods, the inner ring contain 6 rods, the intermediate ring contain 12 rods and the outer ring contain 18 rod. The fuel rods are surrounded by clad from zirconium element and coolant from heavy water. The fuel pin, clad, pressure tube and clanderia data are described in $[6,10,11]$.

The fuel is burnt up to 650 operation days which approximately corresponds to $24 \mathrm{GWd} / \mathrm{T}$. The time steps ranges between 10 and 30 days. Two million neutrons are used to simulate the neutron histories and accumulate the tallies. The geometry of the two bundle model is reflected from all sides which means that neutrons are not allowed to escape from the system.

\section{Results and Discussions}

\subsection{Results without Adjuster Rod}

Fig. 2 illustrates the MCNPX code model vertical view. The model simulates a typical and three dimensional model of the supercell, Fig. 1. Adjuster rod is shown in the figure at the center.

Fig. 3 illustrates the multiplication factor of the MCNPX two bundle model versus operation time up to 650 days with adjuster rod out. The initial multiplication factor is $1.12610 \pm 0.00031$ at zero burn up (fresh fuel), the multiplication factor decreases to 1.08249 after 3 days due to Xenon formation and build up. The multiplication factor starts to increase due to ${ }^{239} \mathrm{Pu}$ accumulation, and then decrease again due to fuel burn up. The present results are compared with Marleau [10] and good agreement was observed up to 500 days of burn up. Table 1 compares between the multiplication factor of the present two bundle

Table 1 Multiplication factor for super cell ( two bundle model) at zero burn up with adjuster rod OUT.

\begin{tabular}{lllll}
\hline Present model & $\begin{array}{l}\text { KENO VI[11] } \\
\text { (Cluster) }\end{array}$ & $\begin{array}{l}\text { KENO VI [11] } \\
\text { (Annular) }\end{array}$ & Dragon code[10] \\
\hline $\mathrm{K}_{\mathrm{eff}}$ & $1.12610 \pm 0.00031$ & $1.13030 \pm 0.00012$ & $1.13109 \pm 0.00012$ & 1.12435 \\
\hline
\end{tabular}

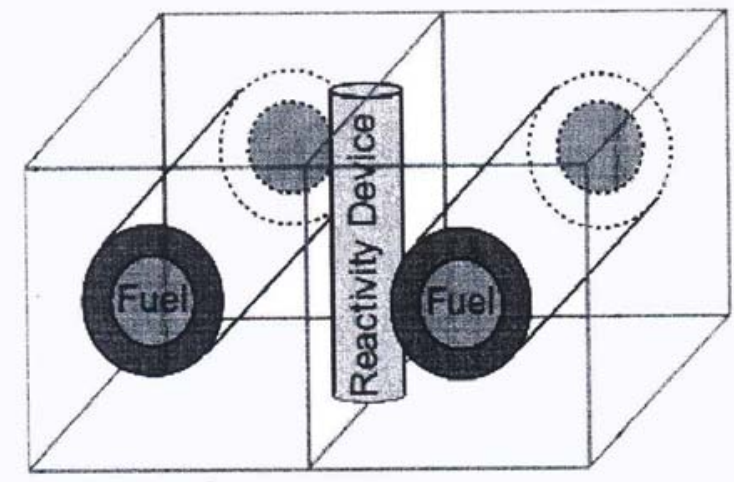

Fig. 1 Three-dimensional super cell.

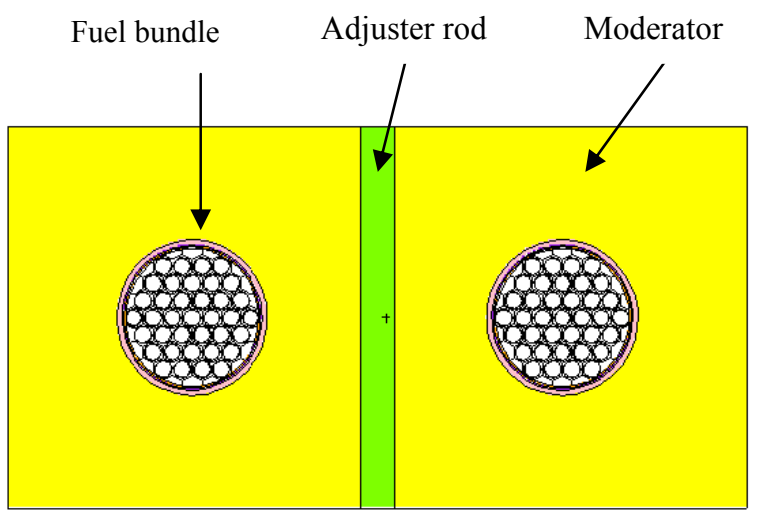

Fig. 2 Vertical model to the two bundle model. 


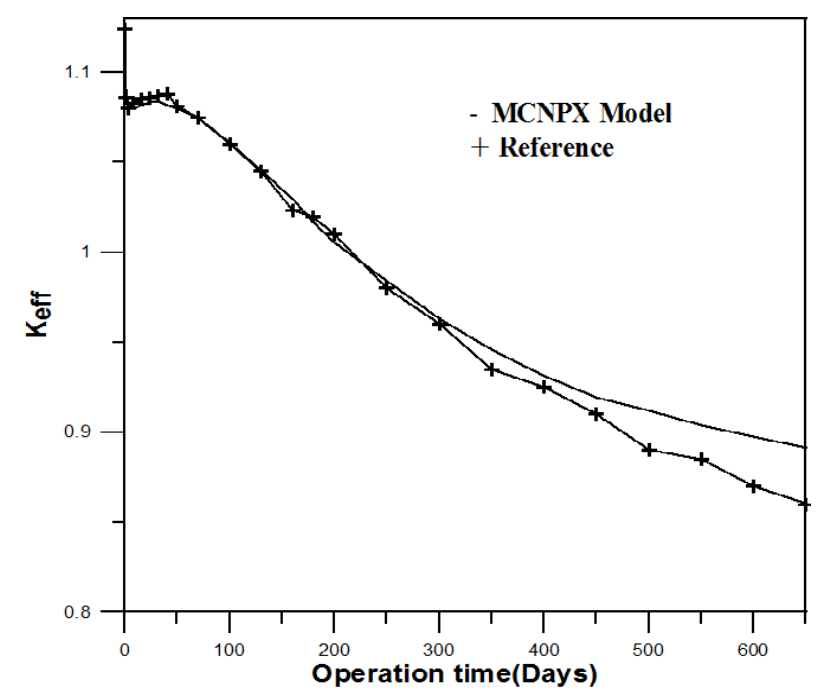

Fig. $3 K_{\text {eff }}$ versus operation time (days).

model and the results of different codes KENO and DRAGON code [10, 11]. In Ref. [11] KENO cluster means the bundle is simulated as 37 fuel rods, and annular means the bundle is represented in the model as three homogenized rings and the central rod. The results indicate good agreement between the present model and those obtained by codes KENO and DRAGON.

Fig. 4 illustrates the multiplication factor versus fuel burn $(\mathrm{Gwd} / \mathrm{T})$.

Fig. $\quad 5 \quad$ illustrates $\quad{ }^{235} \mathrm{U} \quad$ Concentrations (atoms/barn.cm) for fuel element. The results indicate that ${ }^{235} \mathrm{U}$ concentration decreases due to fuel burnup and consumption of the fissile isotope. The results indicate that the ${ }^{235} \mathrm{U}$ concentration reduces from $1.49 \mathrm{E}-4$ (atom/barn.cm) at fresh fuel to $4.575 \mathrm{E}-5$ and $1.78 \mathrm{E}-6$ at operation time corresponds to 200 and 700 days, respectively.

Fig. 6 illustrates Plutonium isotopes ${ }^{239} \mathrm{Pu},{ }^{240} \mathrm{Pu}$, ${ }^{241} \mathrm{Pu}$ and ${ }^{242} \mathrm{Pu}$ concentrations with fuel burnup time. The results show that ${ }^{239} \mathrm{Pu}$ concentrations build up and increase with time, and ${ }^{239} \mathrm{Pu}$ approaches asymptotic with time. Typical ${ }^{239} \mathrm{Pu}$ concentration is 5.724E-5 and 6.609E-5 (atom/barn.cm) at operation time 200 and 700 days respectively.

\subsection{The Effect of Adjuster Rod}

Table 2 illustrates the supercell multiplication factor when the adjuster rod is fully inserted. The results

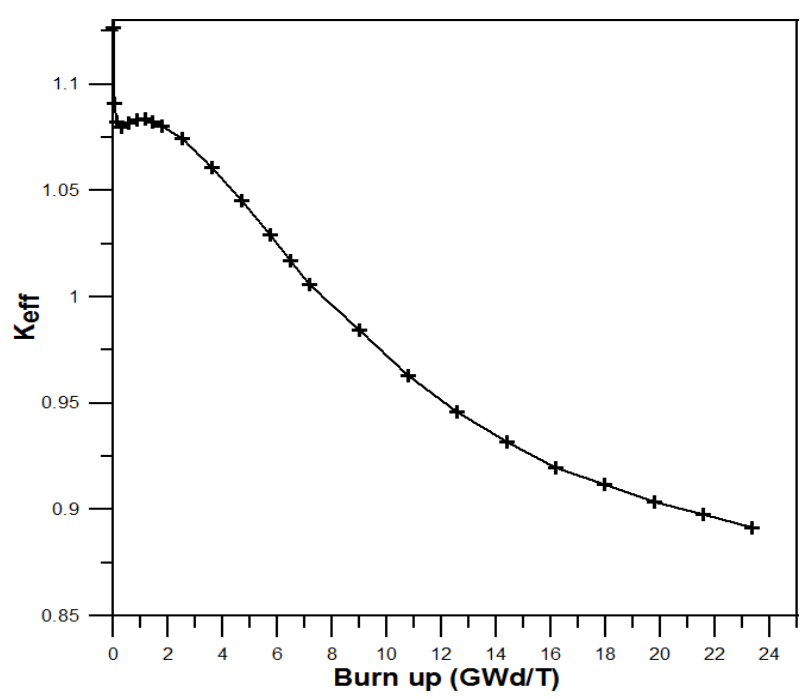

Fig. 4 keff versus Fuel burnup (Gwd/MTU).

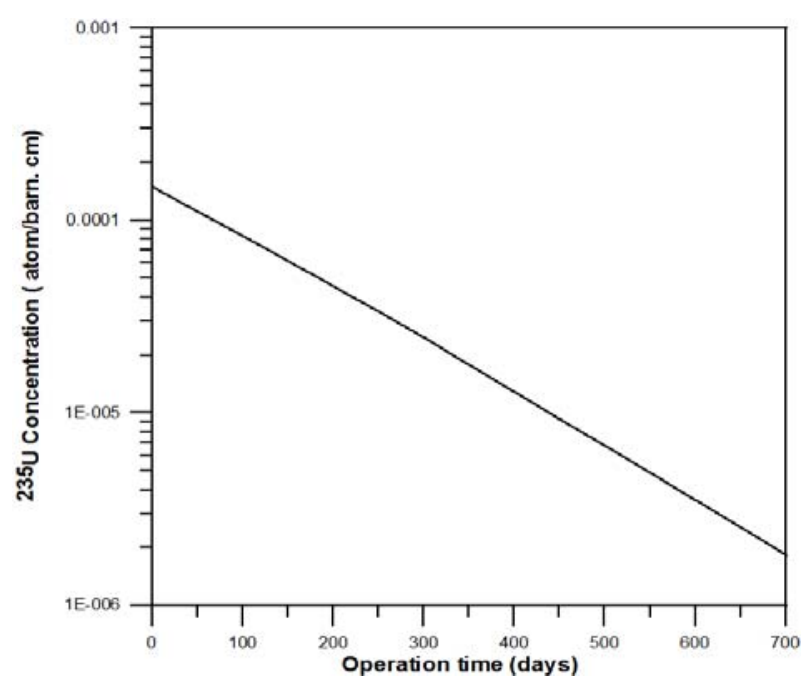

Fig. 5 U-235 Concentration for lattice predicted by MCNPX versus operation time (days).

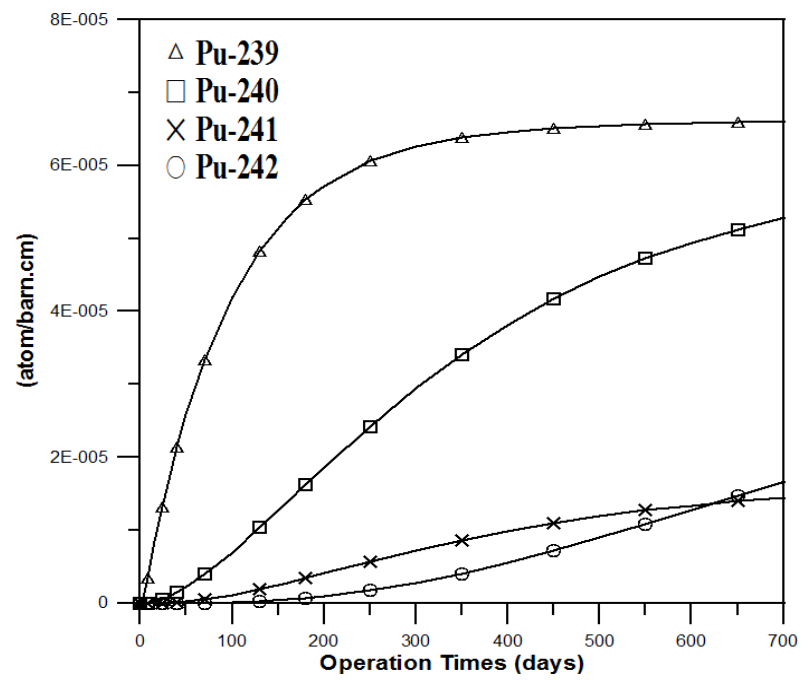

Fig. 6 Plutonium isotopes concentration for lattice predicted by MCNPX versus the operation time (days). 
Table 2 Multiplication factor for two bundle model at zero burn up with adjuster rod IN.

\begin{tabular}{llll}
\hline & Present Model & $\begin{array}{l}\text { KENO VI [11] } \\
\text { (Cluster) }\end{array}$ & $\begin{array}{l}\text { KENO VI [11] } \\
\text { (Annular) }\end{array}$ \\
\hline $\mathrm{K}_{\mathrm{eff}}$ & $1.03840 \pm 0.00034$ & $1.04024 \pm 0.00013$ & $1.04098 \pm 0.00013$ \\
\hline
\end{tabular}

Table 3 Reactivity control adjuster rod worth (pcm).

\begin{tabular}{llll}
\hline & Present model & $\begin{array}{l}\text { KENO VI [11] } \\
\text { ( Cluster) }\end{array}$ & $\begin{array}{l}\text { KENO VI [11] } \\
\text { (Annular) }\end{array}$ \\
\hline Rod worth $(\mathrm{pcm})$ & $-7,499.9$ & $-7,660$ & $-7,653$ \\
\hline
\end{tabular}

compare the present model with KENO (cluster and annular) [11]. Comparison between Tables 1 and 2 we can extract The reactivity worth of the adjuster rod in Table 3 which is calculated from the relation:

$$
\text { worth }=\Delta \mathrm{k} / \mathrm{k}_{1} \mathrm{k}_{2} \text {. }
$$

The results show that the difference is $160 \mathrm{pcm}$ and $153 \mathrm{pcm}$.

\section{Conclusions}

(1) A computer model is designed to simulate the burnup of a supercell fuel and the model predicts the time behavior of neutronic parameters;

(2) Comparison of the fuel bundle multiplication factor with previous published paper showed good agreement with the previous results.

The difference between the worth of the adjuster rod predicted by the present MCNPX model, KINO (cluster) and KINO (annular) are $160 \mathrm{pcm}$ and 153 pcm, respectively.

\section{References}

[1] M. Dahmani, G. Marleau, R.Le. Tellier, Modeling reactivity devices for advanced CANDU reactors using the code DRAGON, Annals of Nuclear Energy 35 (2008) 804-812.

[2] H.B. Choi, S.Y. Kim, C.H. Chung, Incremental cross sections for CANDU-PHWR core analysis, Journal of
Korean Nuclear Society 17 (1985) 98-104.

[3] C.J. Jeong, H. Choi, Compatibility analysis on existing reactivity devices in CANDU 6 reactor for DUPIC fuel cycle, Nuc. Sci and Eng 134 (2000) 265-280.

[4] A.R. Dastur, D. B. Buss, Multicell: A 3-D Program for the Simulation of Reactivity Devices in CANDU Reactors, AECL 07544 Atomic Energy of Canada Limited, 1983.

[5] M. Ovanes, J.V. Donnelly, Validation of 3 dimensional neutron transport calculations of CANDU reactivity devices, Canadian Nuclear Society, 21st Nuclear Simulation Symposium Ottawa, 2000, pp. 1-11.

[6] IAEA TECDOC-887, In core fuel management benchmark for PHWR, International Atomic Energy Agency, Vienna, 1996, pp. 9-159.

[7] J.M. Pounders, F. Rahnema, D. Serghiuta, J. Tholammakkil, A 3D Stylized half core CANDU benchmark problem, Annals of Nuclear Energy 38 (2011) 876-896.

[8] V. Balaceanu, M. pavelescu, Neutronic calculation system for CANDU core based on Transport Methods, Romanian Reports in Physics 63 (2011) 948-960.

[9] MCNPX Computer code package, Los Alamos National Lab. USA, 2006.

[10] R.R. Marleau, J. Tajmouati, D. Rozen, Modeling of CANDU Reactivity control devices with the lattice code dragon, Ann. Nucl. Energy 21 (1994) 115-132.

[11] M.R. Ball, A.C. Morreale, D.R. Novog, J.C. Luxat, The effect on super cell calculations due to modeling CANDU fuel pin clusters as annuli, in: International Conference on mathematics and Computational Methods Applied to Nuclear Science and Engineering, Rio De Janeiro, Brazil, Latin American Section (LAS)/American Nuclear Society (ANS), 2011, pp. 15-21. 